\title{
O PAPEL E OS DESAFIOS DO COORDENADOR PEDAGÓGICO NO COTIDIANO ESCOLAR: UMA ANÁLISE NA REDE PÚBLICA
}

\author{
Vania Marinho Holanda ${ }^{1}$ \\ Marcel Pereira Pordeus ${ }^{2}$
}

RESUMO: Este trabalho aglutina de forma sucinta minha pesquisa de mestrado em Educação. Para tanto, foi embasado com as asseverações de pesquisadores em gestão escolar e políticas públicas educacionais, haja vista discutir alguns desafios enfrentados pelo coordenador pedagógico no cotidiano da escola pública atual e tem como objetivo, refletir e estimular a discussão acerca desses obstáculos, os quais o distanciam do seu foco que é a formação continuada dos docentes na escola. A metodologia usada no desenvolvimento deste estudo foi a pesquisa bibliográficae detalhada em livros, artigos científicos publicados em sites na internet e fontes legais que são diretrizes para a educação nacional. Realizou-se a coleta de dados a partir de um resumo de cada fonte utilizada e a seguir, foi feita uma releitura das obras, respeitando o entendimento de cada autor. Diante do exposto, pôde-se concluir que o coordenador deve ser o profissional mais qualificado para a realização da formação continuada no ambiente escolar, embora, seja consciente de que ainda é preciso aprender a lidar com os muitos desafios que ocorrem na função, o que pode ser minimizado através da ajuda imprescindível do núcleo gestor e dos demais funcionários da escola.

Palavras-chave: Coordenador Pedagógico. Formação continuada. Núcleo Gestor.

\section{INTRODUÇÃO}

O papel e os desafios enfrentados pelos coordenadores pedagógicos de escolas públicas constituem um dos assuntos mais debatidos nas formações acadêmicas. Ao longo dos anos, essa função vem percorrendo diferentes itinerários, no entanto, em virtude das muitas atribuições, o coordenador sente dificuldade em focar nas ações diárias como coordenar,

\footnotetext{
${ }^{\text {I }}$ Possui graduação em Formação de Professores para o Ensino Fundamental pela Universidade Estadual do Ceará (2006). Atualmente é professora da Prefeitura Municipal de Maracanaú. Tem experiência na área de Educação, com ênfase em Ensino-Aprendizagem. Possui especialização em Psicopedagogia Institucional pelo Instituto superior de Teologia aplicada (2010), Área de Educação. Ha 5 anos exerce a função de Coordenadora pedagógica na Escola Edson Queiroz em Maracanaú Ce. E-mail: vaniaholanda5o@gmail.com.

${ }^{2}$ Possui graduação em Letras pela Universidade Federal do Ceará. Mestre em Planejamento e Políticas Públicas pela Universidade Estadual do Ceará. E-mail: marcel.pordeus@aluno.uece.br.
} 
organizar, metodizar e programar os trabalhos pedagógicos, bem como a incentivar a formação e o acompanhamento dos professores na escola.

No cotidiano escolar, o coordenador pedagógico é o profissional incumbido de provocar e suscitar ações efetivamente significativas. Os estudos de Almeida (2003) sobre a função de coordenador no dia a dia das escolas públicas apresentam os desafios que o colocam numa trajetória bem diferente e distante de alcançar sua meta. Nesse sentido, a autora citada ressalta que o ato de ensinar é uma ação intencional, ou seja, implica em atividades planejadas com objetivos claros, acessíveis e possíveis de acontecer, não podendo ficar à mercê de imprevistos, de ações feitas de maneira arranjada ou descompromissada com a aprendizagem do educando.

Dessa forma, o próprio coordenador deve ter a sua rotina de trabalho previamente estabelecida, para que, assim, não perca o seu foco principal.

Placco (2003) apresenta a rotina do coordenador como uma prática marcada por fatos desordenados, que o faz sentir-se frustrado ao invés de contribuir com as atividades educacionais do ambiente escolar. Traz-se à tona, a necessidade de autoavaliação que aprofunde os estudos sobre o tema, refletindo e transformando a sua aplicação diária para que possa ir dia após dia, desconstruindo esse perfil de multiatarefado e centrar-se no seu 1192 verdadeiro foco.

Dessa forma, percebe-se que na função de coordenador pedagógico há uma grande preocupação com orientar o trabalho do docente, seja na sala de aula, nos horários de planejamento ou na aplicação das metodologias de ensino, tal como acompanhar, também, os resultados das avaliações para que se possa traçar metas, desenvolver projetos e pesquisar subsídios que contribuam com o trabalho dos professores.

O objetivo principal dessa pesquisa é, portanto, conhecer o papel do coordenador pedagógico e estimular a discussão acerca dos desafios enfrentados por esse profissional no cotidiano da escola atual. $O$ interesse por este tema surgiu por se sentir a necessidade de compreender o complexo ato de coordenar uma escola pública e a problemática levantada sobre as dificuldades que distanciam os coordenadores de suas metas, impedindo-os de 
acompanhar o desenvolvimento pedagógico escolar e decontribuir satisfatoriamente com a formação dos professores.

Para embasar teoricamente este estudo e definir novos conceitos, foi adotada a pesquisa bibliográfica de autores que abordam o tema estudado como: Almeida (2003), Luck (2009), Placco (2003), Ribeiro (1992) e Saviani (2006) que se dedicaram a investigações nessa área e contribuíram para a reflexão sobre o problema de pesquisa levantado. Contou-se, também, com o estudo da Lei de Diretrizes e Bases (LDB) no que concerne ao tema proposto e de outras fontes legais.

\section{A FUNÇÃO DO COORDENADOR PEDAGÓGICO AO LONGO DA HISTÓRIA EDUCACIONAL NO BRASIL}

Conforme a História e a Legislação Educacional Brasileira, parte da tarefa que hoje é exercida pelos coordenadores pedagógicos esteve, de alguma forma, prenunciada no sistema escolar e associada a outras funções e outros cargos dentro do organograma educacional da época.

Através de seus estudos, Salvador (200o) localiza os antecedentes da 1193

coordenação pedagógica no século XII, na história da inspeção escolar, no período confessional em que a religião exercia grande influência, mais precisamente nas escolas paroquiais, na pessoa dos bispos que as supervisionavam. Posteriormente, com o aumento do número das escolas, a inspeção foi delegada ao mestre escola que acompanhava as atividades nas instituições.

Segundo Ribeiro (1992), logo no início da colonização, a história da educação do Brasil é retratada como sendo uma atribuição da Companhia de Jesus. O primeiro método de ensino ficou conhecido como Ratio Studiorum (sistema educacional dos jesuítas), que estava ligado às necessidades políticas do domínio português e era acompanhado pelos interesses religiosos de catequizar os indígenas na fé da Igreja Católica. Dessa maneira, esse sistema educacional revelava o modelo da sociedade ao qual pertencia, ou seja, o padrão de um povo que recentemente havia sido conquistado e dominado por seus opressores. 
Para Ribeiro (1992), a figura do coordenador pedagógico é apresentada desde o início da história da Educação no Brasil. Logo, com os Jesuítas, via-se claramente essa função sendo exercida com outra nomenclatura, a de 'Prefeito dos Estudos' que, nesse período, trazia entre suas responsabilidades diárias, a de supervisionar a ação do trabalho docente e acompanhar a execução do que foi planejado de acordo com o currículo escolar. Do período colonial até o monárquico, mesmo com todas as reformas que foram realizadas no cenário educacional brasileiro, sempre aparece o vulto desse profissional que supervisiona as ações pedagógicas.

Saviani (2006) refere que, na década de 1930, ocorreu o Movimento Escolanovista, cujo documento denominado 'Manifesto dos Pioneiros da Escola Nova' trazia, como princípio norteador, a modernização do sistema de ensino, que o tornaria laico e gratuito, assegurado como um direito de todos os cidadãos. Desse modo, a oferta educacional deveria se adequar às reais necessidades da demanda da sociedade e de seu público-alvo. Seria uma educação que inseriria os alunos no processo de ensino aprendizagem. Nesse período, a função de coordenador aparece como sendo a de um inspetor escolar.

Já na década de 1960, o papel dos coordenadores é mostrado por Germano (2005) como profissionais que desempenhavam o papel de supervisores, conhecidos também como 1194 especialistas educacionais. Muitos exerciam essa função em várias escolas simultaneamente.

Nesse período, o Brasil passava pelo regime da Ditadura Militar, no qual o supervisor escolar era o especialista que exigia e fiscalizava os educadores, para que cumprissem as orientações advindas do Ministério da Educação e Cultura (MEC), transformando a escola em um ambiente onde se deveria cumprir somente as orientações previamente estabelecidas pelo Governo, sem nenhum tipo de discussão ou debate sobre os temas abordados nas salas de aula.

Segundo Arapiraca (1982, p. IIo),

No contexto da sociedade brasileira, a tecnificação da educação foi intensificada, após o Golpe Militar em 1964, decorrente, sobretudo, do programa de ajuda bilateral ocorrido entre a USAID e o MEC, com o propósito de, através do segmento educativo, legitimar toda uma transformação 'modernizadora' imposta à nacionalidade brasileira, no sentido de direcionar sua racionalidade pelo modo de produção capitalista. 
Com isso, “[...] instituíram-se diversas mudanças no processo do ensino, objetivando modernizá-lo" (PASQUALOTTO, 2003, p. 2). Dessa forma, a escola passou por uma fase de decréscimo, já que todos eram obrigados a cumprir modelos padrões de planos educacionais que antecipavam a ação do docente, deixando-os amarrados aos ideais políticos da época, que vinham de fora do contexto da realidade, além de possuir uma interpretação superficial e obsoleta do cotidiano. Esses planos educacionais contavam com disciplinas em sua grade curricular, que orientavam os estudantes de acordo com as vontades políticas do Governo e que deveriam fazê-los compreender a necessidade de um Regime Militar para o País. Para ratificar essa ideia, disciplinas como Moral e Cívica e Organização Social e Política do Brasil (OSPB) eram obrigatórias em todas as escolas.

Ainda sobre os especialistas educacionais, a Lei de Diretrizes e Bases da Educação no 4.024 de 1961, do artigo 62 ao 64, traçava as orientações de sua função a partir das seguintes exigências:

Art. 62. A formação do orientador de educação será feita em cursos especiais que atendam às condições do grau do tipo de ensino e do meio social a que se destinam. (Revogado pela Lei no 5.692 , de 1971).

Art. 63. Nas faculdades de Filosofia será criado, para a formação de orientadores de educação do ensino médio, curso especial a que terão acesso os licenciados em pedagogia, filosofia, psicologia ou ciências sociais, bem como os diplomados em Educação Física pelas Escolas Superiores de Educação Física e os inspetores federais de ensino, todos com estágio mínimo de três anos no magistério. (Revogado pela Lei no 5.692, de 1971).

Art. 64. Os orientadores de educação do ensino primário serão formados nos institutos de educação em curso especial a que terão acesso os diplomados em escolas normais de grau colegial e em institutos de educação, com estágio mínimo de três anos no magistério primário (BRASIL, 196I).

Saviani (2010), contrapondo-se às ideias dos demais autores, explica que, com a queda do Regime Militar na década de 1980, a função do coordenador passa a ser vista como um cargo que surgiu a partir da necessidade de supervisionar a ação pedagógica nas escolas, dando-lhes mais autonomia. Além disso, suscitava-se o ideal de uma escola mais democrática, que cresceria com a participação ativa de todos os envolvidos no processo educacional. Entretanto, havia também, a necessidade de se repensar o papel dos especialistas que trabalhavam nas escolas. 
Nessa mesma época, ocorreram mudanças drásticas na economia do Brasil. A inflação descontrolada e o crescimento das dívidas com os países estrangeiros colocou a situação financeira e social brasileira em colapso, fazendo-se necessária a implementação de projetos que pudessem reverter este contexto caótico.

\section{I Construção da identidade profissional}

Por mais que o Coordenador Pedagógico venha ganhando, a cada dia, um espaço significativo dentro das instituições escolares, ainda são grandes os debates ao redor da sua identidade. Isso expõe a necessidade de um maior detalhamento a respeito da formação e do verdadeiro papel desse profissional.

O fato é que, como já foi falado, na história da educação brasileira, a função de coordenador pedagógico está enrraizada na ideia de supervisão, na qual atuava exclusivamente como fiscal da educação e propagava uma concepção de combate na representação dos professores. Porém, para fomentar um ensino de qualidade no campo escolar, é essencial ressignificar os saberes, para aplicação da formação continuada nas escolas. É natural que as pessoas busquem conhecer sua identidade profissional; partindo desse pressuposto, o sujeito inserido na sociedade como ser reflexivo e crítico das suas ações, passa por um processo de transformação, constituindo, portanto, sua autossuficiência no meio social. Na situação da identidade profissional do coordenador pedagógico, é indispensável propelir um olhar solidário para sua praxis, reconstruindo sua autoestima, que se propaga negativamente perante as burocráticas exigências e necessidades da prática.

Aprofundar-se nos anseios de uma desvalorizada profissão, como no caso do coordenador pedagógico, constituída nas carências, demandas e complexidades, é remodelar um profissional essencial nas mediações com os professores e na reconstrução de um ensino capacitado defronte dos desafios das inovações.

Outro aspecto fundante da constituição da identidade desse profissional é a "[...] sua história pessoal, trajetória de formação, seus desejos e necessidades e, principalmente, o modo de ingresso na função" (PLACCO; SOUZA, 2012, p. I7). 
Por se formar num período ativo, a cada dia vão sendo acrescentados vários contornos mostrando que o coordenador vigente é, somente, uma recriação dos primeiros do procedimento histórico com outras demandas e exigências geradas no tempo presente. Deste modo, o dever do coordenador pedagógico precisa ser pensado no presente contexto escolar, como especialista que contribui para a instrução do ser social cuja identidade precisa ser repensada, extraindo as amarras da historicidade da educação brasileira e reconstruindo sua função de profissional transformador na escola.

A contribuição desse profissional para a melhoria da qualidade da escola e das condições de trabalho dos professores dependerá do sucesso alcançado nessa tarefa de se conhecer e se estabelecer como um profissional a serviço da organização do trabalho pedagógico. A contribuição desse profissional para a melhoria da qualidade da escola e das condições de trabalho dos professores dependerá do sucesso alcançado nessa tarefa de se conhecer e se estabelecer como um profissional a serviço da organização do trabalho pedagógico.

Conforme as palavras de Fonseca (200I, p. I44), a escola deve,

[...] ser um instrumento de transformação da relidade, resgatar a potência da coletividade, gerar pela esperança, gerar solidariedade e parceria, ser um canal de participação efetiva superando as praticas autoritárias e/ou individualistas, ajudando a superar as imposições ou disputas de vontades individuais, na medida em que há um referencial construido e assumido coletivamente. Aumentar o grau de realização, e portanto, de satisfação de trabalho. Colaborar na formação dos participantes.

Dessa forma, o coordenador educacional estará portando-se como ator social, intermediário e problematizador do papel docente, prezando pelas mediações e direcionamentos mais viáveis ao procedimento de ensino e aprendizagem.

Muitas observações são lançadas sobre a identidade e as atribuições do gestor pedagógico como, por exemplo, a liderança do Projeto Político Pedagógico (PPP), a responsabilidade pelos resultados escolares e as orientações pertinentes aos acontecimentos do cotidiano. Todavia, estudiosos afirmam que o papel central do gestor pedagógico é o de formar os professores, liderando e direcionando os trabalhos pedagógicos na unidade escolar, articulando e transformando a realidade. Nessa perspectiva, se o coordenador conseguir gerir o seu tempo de modo que priorize a formação dos professores, driblará o desafio de construir sua identidade profissional. 


\subsection{O perfil do coordenador pedagógico na escola pública brasileira}

Ao colaborar com uma plataforma de representação do coordenador pedagógico no âmbito da escola pública brasileira, percebe-se que nenhuma influência humana pode ser útil sem a corresponsabilidade e o compartilhamento de ideais. Por esse pretexto, cada perfil pode ser contestado nas unidades de educação, justamente na sala de coordenação, na qual infestam pensamentos e práticas educativas. Todavia, o grande desafio é identificar o perfil do coordenador.

Estando consciente desse momento conflituoso pelo qual passa os profissionais da área, a Fundação Victor Civita resolveu pesquisar sobre o tema levantando dados para formar o perfil do coordenador pedagógico desta década, com a ajuda de profissionais como: Vera Maria Nigro de Souza Placco ${ }^{4}$ (PUC-SP), Laurinda Ramalho de Almeidas (PUC-SP) e de Vera Lucia Trevisan de Souza6 (PUC-Campinas).

Alguns dos dados levantados nesta pesquisa sobre as principais características dos coordenadores pedagógicos brasileiros concluiu-se que $90 \%$ pertencem ao sexo feminino; $88 \%$ já lecionaram nas turmas do I으 ao $9^{\underline{0}}$ ano; $76 \%$ estão em média de 36 a 55 anos e que, na maioria, os entrevistados já possuem mais de cinco anos de experiência nesse cargo. Quanto à 1198 importância do seu trabalho, 95\% afirmaram contribuir significativamente na aprendizagem dos educandos, porém, Ioo\% confirmaram que o foco de seu trabalho é o acompanhamento das atividades pedagógicas com os educadores (PLACCO; ALMEIDA; SOUZA, 2010).

Mesmo com essa consciência de seu papel, apresentam-se dados alarmantes quanto ao desvio de função, o que os fazem se distanciarem de suas metas. Dentre as funções extras mais citadas estão: $72 \%$ acompanham os alunos na entrada e saída da escola; $55 \%$ conferem a ordem e higiene das salas de aula; 50\% atendem aos telefonemas dos familiares e demais pessoas que procuram contato com a escola, e I9\% substituem, pelo menos quatro vezes ao mês, os professores faltosos. Dentre os entrevistados, $9 \%$ confessaram que não realizam

\footnotetext{
${ }^{3}$ Professora da Pontifícia Universidade Católica de São Paulo - PUCSP.

${ }^{4}$ Professora de Pós-graduação da área de Educação da PUC de São Paulo e das Faculdades Oswaldo Cruz.

5 Docente e pesquisadora do Programa de Pós-Graduação Stricto Sensu em Psicologia e do curso de graduação em Psicologia da Pontifícia Universidade Católica de Campinas. Possui graduação em Psicologia (1985), mestrado (1998) e doutorado (2004) em Educação (Psicologia da Educação) pela Pontifícia Universidade Católica de São Paulo (1998).
} 
nenhum tipo de formação continuada com os educadores (PLACCO; ALMEIDA; SOUZA, 2010).

Os coordenadores pedagógicos entrevistados, no momento de mensurar o valor entre diferentes agentes que fazem parte do cenário educacional, se colocaram no sexto lugar, com I\% dos votos. Logo acima, vêm os diretores com 3\%; os governantes com 13\%; os alunos com I8\%; a família com 24\%; e os professores, como personagem principal, com 41\%. Quanto aos problemas que os atrapalham o desenvolvimento de um bom trabalho, foi atestado que a infraestrutura e o acúmulo de afazeres são o que mais os impedem de acompanhar o trabalho pedagógico de formação com os professores. Já em relação à equipe, 31\% têm dificuldades de lidar com os professores desmotivados e em desempenhar ações de liderança. No que se refere à formação do coordenador pedagógico, $96 \%$ atestam que sua graduação foi boa ou excelente, sendo que, desse valor, apenas 21\% apresentaram cursos em gestão escolar (PLACCO; ALMEIDA; SOUZA, 2010).

No final do estudo, foi concluído que a inexatidão na definição dessa função é o que faz o coordenador pedagógico ter múltiplas funções no ambiente escolar, distanciando-o de suas reais obrigações. Isso, talvez ocorra pelo fato de sua própria graduação ser ineficaz para o cargo, contradizendo-se com a avaliação feita pelos profissionais entrevistados.

Almeida (2003) conta que, em 2002, já havia explorado este tema em torno do cotidiano escolar da função de coordenador. Essa é outra pesquisa que foi realizada com ıo coordenadores que faziam parte da rede municipal e estadual da grande São Paulo. Estes apresentam sua rotina de trabalho como sendo algo frenético, agitado ou turbulento. Oito dos dez entrevistados apresentaram a programação e execução dos horários das atividades pedagógicas como uma atividade de um dia típico de trabalho.

São tarefas que giram em torno dos acontecimentos escolares como: questões sobre avaliação; conteúdos; rotina de sala de aula; atividades extraclasses; indisciplina; políticas econômicas; interdisciplinaridade; preparação de materiais usados pelos docentes; leitura dos comunicados; decisões sobre projetose programação das datas comemorativas e dos eventos.

Almeida (2003) ressalta que a maioria dos coordenadores apresenta preocupação devido ao desânimo dos professores nesses momentos de trabalho coletivo e, para isso, sempre 
preparam dinâmicas, textos reflexivos antes das reuniões, ou simplesmente, fazem um momento de escuta para ouvir os desabafos dos professores. A necessidade de ações que fortaleçam o desenvolvimento profissional do docente também é unânime, ainda que seja difícil mobilizar a todos, já que sempre tem aqueles que estão desanimados e apáticos em relação ao trabalho em sala de aula.

Nesse estudo, Almeida (2003) considera que sete dos dez coordenadores, além de planejar e executar o horário de estudo, têm, também, que organizar a entrada dos alunos no início dos períodos, verificando o número de professores presentes e ausentes e identificando possíveis aulas vagas.

A falta de professores, frequentemente, é outro desafio enfrentado pelos coordenadores no ambiente escolar. Isso reverbera em outras situações, como no fato do coordenador assumir a turma que ficou descoberta, com os alunos ociosos, caso não tenha alguém para substituí-lo, já que a escola não conta com um número suficiente de funcionários para suprir a demanda de faltas.

Outro desafio elencado trata das relações interpessoais entre professores, pais e alunos, pois além de organizar e executar os horários dos trabalhos pedagógicos, ainda precisa ficar atendendo a casos particulares e individuais que envolvem pais, professores e alunos 1200 devido a conflitos e desentendimentos no ambiente escolar. Muitas vezes, isso ocorre de maneira súbita, em momentos inadequados, nos quais o coordenador deixa o acompanhamento ou estudo com os demais professores que estão planejando, para ser o apaziguador de situações de indisciplina.

Quanto ao desafio das relações interpessoais foi citado o temperamento e a formação deficitária dos professores e as concepções que os mesmos trazem sobre o papel da escola, os direitos e deveres dos alunos e dos próprios professores. Logo, os coordenadores estão conscientes de que, por muitas vezes, não realizam um bom trabalho e não atendem às expectativas do grupo docente, devido às eventuais situações que se apresentam, fazendo com que os mesmos se ausentem de suas reais funções para buscarem soluções para esses problemas. 


\section{CONSIDERAÇÕES FINAIS}

O estudo realizado possibilitou apresentar algumas considerações sobre o papel e os desafios enfrentados pelo coordenador pedagógico no cotidiano da escola atual. A escolha do tema surgiu a partir de questionamentos sobre a verdadeira função desse profissional e acerca dos problemas que surgem diariamente no seu trabalho. Recorrendo a várias literaturas, constatou-se que o coordenador pedagógico, na atualidade, exerce ainda uma função repleta de desafios, o que constitui obstáculos para o desempenho qualitativo das atividades realizadas no âmbito escolar.

Verificou-se, também, que a sobrecarga de trabalho e desvios de função muitas vezes culmina em uma atuação desordenada, ansiosa, imediatista e desfocada da real atribuição que lhe cabe. Esta pesquisa atingiu, portanto, o seu objetivo principal que é conhecer o papel do coordenador pedagógico, bem como, refletir e estimular a discussão sobre os desafios enfrentados por esse educador na atualidade.

Como resultado, fica claro que o seu papel principal na rotina escolar e nos processos de ensino e aprendizagem, é enfatizar a mediação e a articulação com os professores na formação continuada e também a construção de ações coletivas, seja na busca da aplicação 1201

prática do Projeto Político Pedagógico (PPP), seja na reflexão de ações que visem à superação de situações problemas no ambiente educativo e, sobretudo, na construção de ações integradoras da equipe escolar.

O coordenador deve oferecer também condições para que os professores trabalhem coletivamente as propostas curriculares, auxiliando no planejamento de estratégias mais adequadas à realidade específica dos alunos, de modo que o processo ensino-aprendizagem seja favorecido. Enfim, esta pesquisa possibilitou compreender que o coordenador pedagógico é um profissional polivalente que se desdobra em muitas funções; todavia, seu papel mais importante nas unidades escolares é a formação continuada dos docentes, visando profissionais motivados e melhores resultados dos seus alunos em todos os aspectos.

Muitos estudos ainda se fazem necessário sobre esse tema. Recomenda-se, portanto, desdobramentos futuros da pesquisa desenvolvida. 


\section{REFERÊNCIAS}

ALMEIDA, L. R. de. Um dia na vida do Coordenador Pedagógico. In: ALMEIDA, L. R. de. PLACCO. V. M. N. S. O Coordenador Pedagógico e o cotidiano da escola. São Paulo: Ed. Loyola, 2003.

ALMEIDA, Laurinda Ramalho de. Um dia na vida de um coordenador pedagógico de uma escola pública. In: PLACCO, Vera Maria N. de Souza e ALMEIDA, Laurinda Ramalho de (Org.). O coordenador pedagógico e o cotidiano da escola. São Paulo: Edições Loyola, 2010.

ALMEIDA, Laurinda Ramalho de. O relacionamento interpessoal na coordenação pedagógica. São Paulo: Loyola, 2003.

ARAPIRACA, J. O. A USAID e a Educação Brasileira. São Paulo: Autores Associados, 1982. (Coleção Educação contemporânea: Série Memória da Educação).

BRASIL. Lei 4.024, de 20 de dezembro de 196ı. Fixa as Diretrizes e Bases da Educação Nacional. Brasília, DF, i96r. Disponível em:

〈http://www.planalto.gov.br/ccivil_03/leis/14024.htm>. Acesso em: 9 de fev. 2017.

BRASIL. Lei n. 9394, de 20 de dezembro de 1996. Estabelece as Diretrizes e Bases da Educação Nacional. Disponível em: <http:// www.planalto.gov.br/ccivil_03/leis/19394.htm Acesso em: Io fev. 2017.

FONSECA, J. P. Projeto pedagógico: processo e produto na construção coletiva do sucesso escolar. São Paulo-SP: Jornal da APASE. Secretaria de Educação. São Paulo.SP. Ano II - Noo. 03, 200I.

GERMANO, José Willington. Estado militar e educação no Brasil (1964-1985). 4. ed., São Paulo: Cortez, 2005.

PASQUALOTTO, L. C. Educação a Distância Entre Mitos e Desafios Frente ao Processo de Mercadorização da Educação. [Dissertação de Mestrado]. Universidade

PLACCO, Vera M. N. S.; ALMEIDA, Laurinda R. (Orgs). O Coordenador pedagógico e o cotidiano da escola. São Paulo: Loyola, 2003.

PLACCO V. M. N. S. O Coordenador Pedagógico no confronto com o cotidiano da escola. In: ALMEIDA, L. R. de. PLACCO. V. M. N. S. O Coordenador Pedagógico e o cotidiano daescola. 4. ed. São Paulo: Loyola, 2003.

RIBEIRO, Maria Luiza Santos. História da educação brasileira: a organização escolar. São Paulo: Cortez Autores Associados, 1992.

SALVADOR. C.M. Ocoordenadorpedagogico na ambiguidade interdisciplinar. [Dissertação 


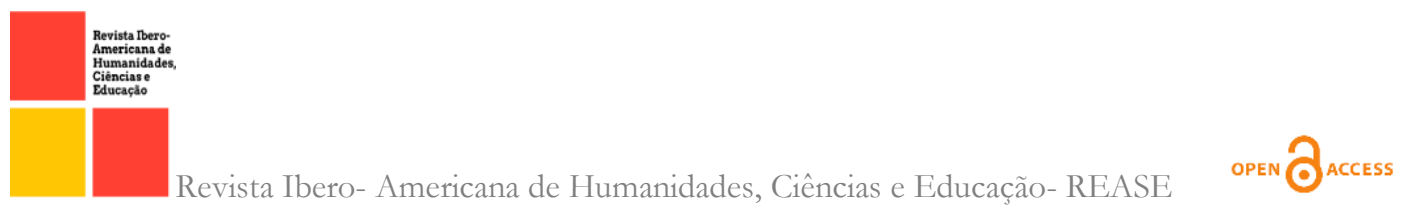

de Mestrado]. Programa de Pós-graduação em Educação.SãoPaulo: Pontifícia Universidade Católica, 2000.

SAVIANI, Dermeval. A supervisão educacional em perspectiva histórica: da função à profissão pela mediação da ideia. In: FERREIRA. N. S. C. Supervisão educacional para uma escola de qualidade. 5. ed. São Paulo: Cortez, 2006c. 